\title{
Das Experiment: Revierverhalten bei Vögeln
}

Während die Ausbildung von Studenten auf dem Gebiet der Verhaltensforschung insbesondere im Rahmen eines Großpraktikums kein prinzipielles Problem darstellt, ergeben sich für die Ausbildung von Schülern auf diesem Gebiet große Schwierigkeiten. Einerseits nimmt in der Oberstufe die Verhaltensforschung einen relativ breiten Raum ein. Andererseits ist es gerade in diesem Gebiet recht schwierig, den Unterricht experimentell zu unterstützen, da solche Experimente meist neben der theoretischen Einarbeisung auch sehr viel Zeit für die praktische Vorbereitung benötigen. Außerdem sind die Versuchsergebnisse häufig nur durch Beobachtungen über längere Zeiträume zu erhalten, so daß sie sich auch aus diesem Grund nur schlecht für den Unterricht eignen.

Im folgenden soll daher eine experimentelle Methode beschrieben werden, mit deren Hilfe auch im Schulunterricht einfache Verhaltensstudien an Vögeln durchgeführt werden können, ohne daß dabei die geschilderten Nachteile in Kauf genommen werden müssen. Gleichzeitig besitzt die Methode den Vorteil, daß die Beobachtungen an frei lebenden Tieren durchgeführt werden, während diese sonst zumindest für Wirbeltiere während des Unterrichts nahezu ausgeschlossen sind.

Die Versuche können nur im jeweiligen Vogelrevier selbst oder in seiner unmittelbaren Nähe angestellt werden. Die Experimente lassen sich daher je nach Lage der Schule für eine verschiedene Zahl von Vogelarten vom Unterrichtsraum aus durchführen. Will man Vogelarten untersuchen, deren Reviere sich nicht in unmittelbarer Nähe der Schule befinden, so müssen die Experimente im Freien vorgenommen werden.

Die apparativen Voraussetzungen sind sehr gering. Benötigt wird neben einem Tonbandgerät (Kassettenrecorder genügt, für Versuche im Freien mit Batteriebetrieb), das einen Anschluß für einen Außenlautsprecher besitzen muß, ein einfacher kleiner Lautsprecher ohne Verkleidung (Durchmesser 5$10 \mathrm{~cm}$, ca. $5 \mathrm{Ohm}$, Preis ca. 15,- DM). Für Experimente vom Unterrichtsraum aus können selbstverständlich auch vorhandene größere Lautsprecher verwandt werden. Außerdem braucht man 20-30 m Kabel, über die der Lautsprecher vom Tonband aus betrieben werden kann. Zur Beobachtung der Vögel sind Ferngläser vorteilhaft, aber keineswegs notwendig.
Zur Vorbereitung des Experiments wird der Lautsprecher in $10-30 \mathrm{~m}$ Entfernung von den Beobachtern an einem Strauch, Baum, Zaun o. ä. aufgehängt. Die Wahl der Entfernung und des Lautsprecherplatzes hängt von der Revierstruktur, der Störanfälligkeit und den Verhaltensmerkmalen des jeweiligen Vogels ab sowie vom Standplatz und der Größe der beobachtenden Gruppe. Der vorher auf Tonband aufgenommene Gesang (s.u.) der angepeilten Vogelart wird dann über den Lautsprecher abgespielt (der Lautsprecher im Tonbandgerät muß dabei abgeschaltet sein!). Das revierbesitzende Männchen findet sich nach kurzer Zeit in der Nähe des Lautsprechers ein, um den vermeintlichen Eindringling aus dem Revier zu vertreiben. Der Vogel und sein Verhalten können nun in aller Ruhe von den Schülern beobachtet werden.

Für Schüler der Unterstufe eignet sich diese Methode zur einfachen Demonstration der verschiedenen Vertreter einheimischer Vögel. Mit Hilfe von Bildbänden (z.B. [4, 6, 8]) können die einzelnen Vogelarten von den Schülern bequem bestimmt werden, da die Beobachtungszeit durch wiederholtes Abspielen des Gesangs ausreichend verlängert werden kann. Für Schüler der Oberstufe wird der Schwerpunkt auf die Beobachtung der einzelnen Verhaltensweisen des Vogels gelegt werden. Je nach Vogelart können dabei die verschiedenen Formen von Droh- und Kampfverhalten beobachtet werden. Die wichtigsten dieser Verhaltensweisen, die hier nur summarisch wiedergegeben werden können, sind ritualisierte Intensionsbewegungen wie z.B. Teile des Imponiergehabes (Aufplustern des Gefieders), Úbersprungsverhalten (Gefiederputzen, scheinbare Nahrungsaufnahme) sowie typische Eigenschaften des Revierverhaltens. Zur genaueren Beschreibung dieser Verhaltensweisen sei auf die Literatur verwiesen (z.B. [3, 7, 9]). Neben der Verwendung im normalen Unterricht eignet sich diese Methode auch zu quantitativen Untersuchungen [5], die in Arbeitsgemeinschaften (oder auch im Rahmen des Wettbewerbs ,Jugend forscht') durchgeführt werden können und direkt in die praktische Vogelkunde überleiten würden [2].

Die Zahl der Vogelarten, die sich auf diese Weise zu irgendeiner Reaktion bis hin zum aggressiven Verhalten in Lautsprechernähe stimulieren läßt, ist sehr groß und reicht von den Meisen, Grasmücken, Laubsängern, Baumläufern, dem Zaunkönig und den
Ammern bis hin zu den Spechten, Eulen u.a. Die beste Aussicht auf ein erfolgreiches Ansprechen bieten die Vogelarten in der Zeit des ausgeprägtesten Revierverhaltens, also während der Werbung um das Weibchen, dem Nestbau und der Jungenaufzucht. Dies vollzieht sich in etwa zwischen März und Juli. Außer der Jahreszeit sollte auch die Tageszeit beim Experiment berücksichtigt werden, denn die Singvögel z.B. sprechen in der Regel in den Morgenstunden (etwa 5-10 Uhr) wesentlich besser an als in der Mittagszeit.

Vor der praktischen Durchführung der beschriebenen Methode im Unterricht sollten Fragen der jeweiligen Revierlage, Reviergröße, Erreichbarkeit, auch die Reaktionsbereitschaft der vorgesehenen Vogelarten vorsichtshalber erst einmal vom Lehrer selbst kontrolliert werden, da gerade bei dieser Art von Versuchen die eigene Erfahrung eine große Rolle spielt. Gezieltere Hinweise mit allgemeiner Gültigkeit lassen sich hier wegen der großen Verhaltensunterschiede der einzelnen Vogelarten nicht geben.

Von einer Einbeziehung seltener oder in ihrem Bestand gefährdeter Vogelarten ([2], sowie aktuelle "Rote Listen“ der Vogelschutzwarten oder vergleichbarer Einrichtungen) ist prinzipiell Abstand $\mathrm{zu}$ nehmen, da diese Verhaltensstudien immerhin eine Störung darstellen, die man angesichts der zahlreichen schädigenden Umwelteinflüsse (vgl. z.B. [1]) den gefährdeten Arten nicht noch zusätzlich zumuten darf. Bei den anderen Vogelarten sollten die Experimente aber auch nur verantwortungsvoll dosiert geboten werden, d.h. nicht längere Zeit am selben Tag und nicht häufiger am selben Individuum in der laufenden Brutsaison.

Besonderes Augenmerk muß auch darauf gerichtet werden, daß die beobachtende Gruppe nicht unnötige oder unverantwortliche Biotopveränderungen verursachen kann und verursacht.

Zum Schluß soll noch kurz darauf eingegangen werden, wie die Gesangsaufnahmen erhalten werden können. Im Prinzip kann der Artgesang zwar jeweils selbst aufgenommen werden. Allerdings ist dazu ein Richtmikrophon oder noch besser ein Parabolreflektor mit entsprechendem Mikrophon nötig. Auch sollten an die Qualität des Tonbandgerätes für die Aufnahmen höhere Anforderungen gestellt werden. Sehr viel einfacher erhält 


\section{biuz aktuell}

man jedoch die Gesangsaufnahmen, indem man sie von einer der käuflichen Schallplatten (z.B. Kosmophon Vogelstimmenplatten) überspielt. Zum Teil sind VogelstimmenSchallplatten auch bei den Landesbildstellen erhältlich.

\section{Literatur}

[1] Berthold, P. (1972): Uber Rückgangserscheinungen und deren mögliche Ursache bei Singvögeln. Vogelwelt 93, 216-226.

[2] Berthold, P., E. Bezzel und G. Thielcke (1974): Praktische Vogelkunde. Kilda-Verlag, Greven.

[3] Blume, D. (1971): So verhalten sich die Vögel. Franckh'sche Verlagshandlung, Stuttgart.

[4] Heinroth, K. (1962): Mitteleuropäische Vögel. Kronen-Verlag, Hamburg.

[5] Helb, H.-W. (1973): Analyse der artisolierenden Parameter im Gesang des Fitis (Phylloscopus t. trochilus) mit Untersuchungen zur Objektivierung der analytischen Methode. J. Orn. 114, 145-206.

[6] König, C. (1966-1970): Europäische Vögel. Bände 1-3. Belser Verlag, Stuttgart.

[7] Lamprecht, J. (1972): Verhalten. Herder Verlag, Freiburg-Basel-Wien.

[8] Peterson, R., G. Mountfort und P. A. D. Hollom (1973): Die Vögel Europas. 10. Auflage. Parey Verlag, Hamburg u. Berlin.

[9] Thielcke, G. (1970): Vogelstimmen. Springer-Verlag, Berlin-Heidelberg-New York.

\section{Dr. Hans-Wolfgang Helb \\ Dr. Holk Cruse}

Fachbereich Biologie der Universität

D-6750 Kaiserslautern, Postfach 3049

\section{Gen-Manipulation}

Vom 10. bis 12. Oktober veranstaltete das Wissenschaftliche Studienzentrum FORUM DAVOS in Zusammenarbeit mit dem Duttweiler Institut und der Schweizerischen Gesellschaft für Zell- und Molekularbiologie einen Kongreß über Genmanipulation. Die Offentlichkeit, vertreten durch interessierte Laien verschiedenster Fachrichtungen sowie durch Presse und Rundfunk, sollte über die Möglichkeiten und Grenzen von Eingriffen in die Erbsubstanz informiert werden. Bei den von kompetenten Spezialisten gehaltenen Vorträgen wie auch bei den anschließenden Panel- und Plenumsgesprächen ging es einerseits um das Aufzeigen neuester genetischer Forschungsergebnisse und andererseits um gesellschaftliche, soziologische und ethische Probleme als Folge der genetischen Forschung, oder besser der gesamten modernen Naturwissenschaft, denn es zeigte sich bald, daß die angesprochenen Probleme die NaturForschung in ihrer ganzen Breite betreffen. Hauptreferent zum Thema "Neue Möglichkeiten der Genmanipulation" war P. Berg (Stanford University), einer der Initiatoren des kürzlich veröffentlichten ForschungsMoratoriums (biuz 4, 1974, S. 159). Er berichtete über die in mehreren kalifornischen Labors entwickelten Methoden zur Klonierung bestimmter eukaryotischer DNA-Bereiche in Bakterien. Dies geschieht im Prinzip so: Mit hochspezifischen Nukleasen (sog. Restriktionsenzymen) wird doppelsträngige DNA in vitro an definierten Stellen (bestimmt durch eine Nukleotidsequenz, die vom Restriktionsenzym erkannt wird) gespalten. Da dabei die beiden DNA-Stränge der doppelsträngigen DNA nicht genau gegenüber, sondern treppenartig versetzt gespalten werden, entstehen bei dieser Hydrolyse doppelsträngige DNA-Moleküle mit kurzen, zueinander komplementären einzelsträngigen Enden. Und diese erlauben nun, daß DNA-Fragmente von verschiedenstem Ursprung, die durch Spaltungen von DNA mit dem gleichen Restriktionsenzym entstanden sind und somit gleiche EinzelstrangEnden besitzen, zu neuen "hybriden“ DNAMolekülen enzymatisch (kovalent) miteinander verknüpft werden können. Die so entstandenen DNA-Moleküle müssen dann zur in vivo Vermehrung durch Transformation in Zellen eingebracht werden, wo sie je nach DNA-Kombination als Plasmid oder integriert im Chromosom repliziert und eventuell auch exprimiert werden. Augenblickliche Anwendung findet diese Methodik u.a. bei der Kopplung von DNA des Krallenfrosches Xenopus oder der Taufliege Drosophila an die DNA bestimmter Plasmide des Bakteriums Escherichia coli und anschließender Replikation dieser hybriden DNA-Moleküle in E.coli-Zellen. So können eukaryotische DNA-Bereiche, die bestimmte Gene enthalten, aus der Komplexität des Gesamtchrosoms herausgelöst, gezielt vermehrt werden und die biochemischen Reaktionen ihrer Expression näher studiert werden - sicherlich ein wesentlicher methodischer Fortschritt für die Untersuchung der komplexen Reaktion der Genexpression und Differenzierung eukaryotischer DNA. In diesem Zusammenhang wurde die Möglichkeit diskutiert, für die medizinische Anwendung wichtige Genprodukte wie z.B. Insulin, Wachstumshormone oder Vitamine mit Hilfe der neuen Methodik in großen Mengen über Bakterienzüchtungen herstellen zu können. Da es aber bis heute, wie M. Birnstiel(UniversitätZürich) ausführte, nur in wenigen Fällen (wie z.B. bei den Genen für ribosomale RNA von Xenopus laevis) gelungen ist, die DNA eines Gens frei von zusätzlicher DNA zu isolieren, besteht bei solchen Versuchen die Gefahr, daß zusammen mit den gewünschten Genen auch eukaryotische DNA unbekannter Funktion in Humanbakterien eingeführt wird, was negative Folgen haben könnte.

Dieser Aspekt sowie mögliche Gefahren, die das Einbringen von Tumorviren-DNA in bakterielle Chromosomen oder das genetische Manipulieren mit Antibiotika-ResistenzFaktoren mit sich bringen, waren ja der unmittelbare Anlaß zu dem erwähnten Forschungsmoratorium. Wie P. Berg ergänzend sagte, sei dieses Moratorium aber nicht gedacht als Katalysator zum allgemeinen Uberdenken der gesellschaftlichen und ethischen Relevanz moderner biologischer Forschung mit dem Versuch, gewisse Forschungsmöglichkeiten nicht auszunutzen, sondern dieses Moratorium solle nur einen Aufschub gewisser Forschungsarbeiten bewirken, um unter Berücksichtigung aller Parameter mögliche Gefahren für die öffentliche Gesundheit zu erkennen und zu vermeiden. Die Grundlagenforschung - und als Hilfsmittel für diese wird die neue Genmanipulationsmethodik angesehen - solle freibleiben von jeglicher Lenkung. An diesem Punkt entbrannte eine lebhafte Diskussion, da E. von Weizsäcker (Universität Essen), unterstützt von einem Teil der Tagungsteilnehmer, befürchteten, daß eine ungehemmte Weitererforschung der biologischen Umwelt in den Folgewirkungen 